by irradiation; unfortunately, the dosage required to exterminate the bacteria sometimes renders the food unpalatable, a difficulty which has still to be overcome. An even more attractive application is in the sterilization of certain types of pharmaceutical products; due to chemical instability or unfavourable physical properties, it may not be possible to use the usual high-temperature methods of sterilization, and irradiation may be used with a temperature rise of a few degrees only. In addition, the product may often be treated in its finally packaged state, ready for distribution.

The irradiation of polymeric substances frequently results in useful changes of their properties. These changes may be roughly classified into two types. In the first of these $\mathrm{C}-\mathrm{H}$ bonds are ruptured to give a hydrogen atom and a free polymer radical. Two radicals combine to give a larger molecule, a process known as cross-linking, and a molecule of hydrogen is liberated. If the irradiation dosage is large, so many cross-linkages may be formed that the whole specimen becomes virtually a single huge molecule which is extremely inert chemically and insoluble in most solvents. The other type of change which may occur is known as degradation. The polymer is broken down into simpler hydrocarbons, some of which are gaseous and held in the substance under high pressure. Subsequent heating of the polymer softens it and allows this gas to expand, thus producing a foamed material the low density and other characteristic properties of which have found useful applications.

The new laboratory has been set up by Metropolitan-Vickers to provide an irradiation service for other industrial firms and organizations. In doing so the Company has demonstrated a degree of initiative which one hopes will be matched by its potential customers. It is pleasant to witness an industrial enterprise which is not content merely to keep abreast of current scientific advance but which also itself makes a noteworthy contribution to scientific progress.

\title{
THE PROGRESS OF WORLD HEALTH
}

$\mathrm{O}$ $\mathrm{N}$ April 7 the World Health Organization marked its tenth anniversary by sponsoring the celebration, on that date, of a World Health Day in London. As its director-general, Dr. M. G. Candau, said, there have been, during the past ten years, great scientific advances-new drugs, new vaccines, new and better insecticides, more effective methods of fighting or preventing disease. Governments have learnt to take responsibility for the health of their peoples and to provide not only hospitals and health institutions, but also better food and better care fo mothers and the young; and eighty-eight countries are now members of the World Health Organization.

How much has been achieved was outlined by Dr. H. van Zile Hyde, chief of the United States Division of International Health. Infectious disease has handicapped man throughout his history. History has, in fact, often been changed by diseases such as typhus, influenza, plague and malaria. But in limited areas of the world in which it has been possible to apply the knowledge acquired by medical science, the epidemics of the past - cholera, smallpox, plague and yellow fever-are no longer feared. Malaria, prevalent in regions in which three-fourths of mankind live, has been conquered to such an extent that whereas, in 1948,300 million people had malaria each year and 3 million died of it, these figures have to-day been cut by 30 per cent. This disease is still one of the most formidable menaces, but its eradication, already achieved in certain areas, is now possible almost everywhere in the world. It is likely that it will, in a few years, be controlled in the United States, and no new infections with it are expected in the U.S.S.R: after 1960. In the eastern Mediterranean, a traditional reservoir of the disease, great progress in its control has been made. The most serious problem is presented by Africa south of the Sahara, but here also much has been achieved.

The list of other scourges controlled is long and encouraging. Respiratory diseases, such as pneumonia, the common cold and influenza, still flourish ; but whooping cough, though it still resists, is in retreat. The international spread of epidemic diseases, formerly controlled by quarantine regulations which imposed great hardships and delays in travel and commerce, is now reduced, in spite of increased possibilities of spread of these diseases by the aeroplane, to the relatively easy conditions of the International Sanitary Regulations designed by the World Health Organization and adopted in 1951 .

Many diseases formerly feared, such as cholera, typhus, smallpox, yellow fever, tuberculosis, and those menaces of childhood, scarlet fever, measles and diphtheria, are now virtually under control and, if they occur and are properly handled, they rarely kill. The decline of mortality is, in fact, one of the most significant features of the health record of the world, but it creates new problems that are serious. More elderly people must be fed and housed and given work ; the diseases of later life, such as cancer, diabetes and heart disease, are commoner. The stress of modern life is also taking its toll, and great quantities of drugs are manufactured to counter this stress. Whereas infectious and parasitic diseases have been reduced by half, accidents, especially among the young, are leading causes of death. For the very young, on the other hand, and for the mothers who bear them, there is much greater chance of health and happy life.

Thus people born nowadays may expect, apart from accidents, a safer, longer and happier life than earlier generations could. They owe this, of course, primarily to the work of men and women of all nations who have provided the knowledge on which this remarkable progress has been based, and also to the work of the World Health Organization and kindred organizations which have integrated and correlated the work done by individuals and teams in various parts of the world. A major problem of the future would seem to be the diseases of later life, such as cancer, diabetes and arteriosclerosis. If so much has been done in a decade, there is every hope that these diseases also will soon be added to the list of scourges that man has overcome.

G. Lapage 